\title{
Educação das Relações Étnico-Raciais e o Ensino de Música: notas sobre a operacionalização do conhecimento étnico nas práticas escolares
}

Ethnic-Racial Relations and Music Teaching: considerations of ethnic knowledge in school practices

Rodrigo Cantos Savelli Gomes* Secretaria Municipal de Educação de Florianópolis/ Universidade Federal de Santa Catarina rodrigocantos@hotmail.com

*Doutorando em Antropologia Social pela UFSC. Mestre em Musicologia-Etnomusicologia e licenciado em Música pela UDESC. Professor efetivo da Secretaria Municipal de Educação de Florianópolis.

Submetido em 23/04/2018, Aprovado em 26/11/2018 


\section{Resumo}

O presente ensaio problematiza a educação das relações étnico-raciais para além de um "conteúdo" dos componentes curriculares, mas principalmente como uma abertura para diferentes epistemologias, cosmologias, para diferentes possiblidades de transmissão e produção do conhecimento. Isto implica revisão de valores e conceitos, reposicionamento de hierarquias, modificações das estruturas espaciais, entre outros aspectos. Com base nesta perspectiva, apresento algumas reflexões a partir de minha atuação enquanto professor do Ensino Fundamental na disciplina artes-música, em diálogo com as teorias antropológicas e etnomusicológicas, áreas que cursei no mestrado e doutorado enquanto trabalhava na escola. Recorro as noções teóricas de "escola como fronteira" (TASSINARI, 2012), "disposições adequadas" (INGOLD, 2000), "ouvido dançante" (OLIVEIRA, 2015), "musicalização do outro" (HILL, 2014) em paralelo às reflexões das vivências escolares. Bus$\mathrm{co}$, com isso, refletir criticamente sobre a escolarização dos conhecimentos, sobre as rotinas escolares que impedem o reconhecimento de outras formas de aprendizagem, assim como apontar outras formas de se relacionar com os saberes e de produzi-los.

Palavras-chave: produção de conhecimento; diversidade étnico-racial; práticas escolares.

\section{Abstract}

This paper discusses the ethnic-racial education not only as a "content" of the curricular components, but mainly as a process of expansion for different epistemologies, cosmologies, for different possibilities of transmission and production of knowledge. This implies a revision of values and concepts, repositioning of hierarchies, modifications of spatial structures, among other aspects. From this perspective I present some reflections about my job as a primary school teacher in the arts-music discipline, at the same time in dialogue with the anthropological and ethnomusicological theories, areas that I studied in master and doctorate degree while was working in school. I discuss theoretical notions of "school as frontier" (TASSINARI, 2012), "appropriate dispositions" (INGOLD, 2000), "dancing ear" (OLIVEIRA, 2015), "musicalization of the other" (HILL, 2014) at the same time with the school experiences. With this, I try to problematize the school knowledge, the routines that do not allow the validation of other ways of learning, other ways of relating to and producing knowledge.

Keywords: knowledge production; ethnic-racial diversity; school practices. 
A atenção com a diversidade étnico-racial vem sendo objeto de leis, diretrizes e documentos oficiais produzidos nas últimas décadas para o Ensino Básico no Brasil. Pode-se dizer que desde a implementação da LDB 9.394/96 o tema da diversidade étnico-racial passou a estar presente de forma significativa em praticamente todos os documentos oficiais, municipais, estaduais e nacionais direcionados à educação. Os caminhos e possibilidades para sua implementação vem sendo tema de ampla discussão no meio educacional por meio de congressos, seminários, formação específica para professores, publicação de artigos, livros, fóruns, entre outros.

Nos últimos anos, além das Leis 10.639/03 e 11.645/08, foram produzidos diretrizes e documentos oficiais específicos para a implementação da diversidade étnico-racial, como por exemplo: Diretrizes Curriculares Nacionais para a Educação das Relações Étnico-Raciais e para o Ensino de História e Cultura Afro-Brasileira e Africana (2004); Orientações Curriculares: expectativas de aprendizagem para a Educação Étnico-Racial na educação infantil, ensino fundamental e médio (2008); Plano Nacional de Implementação das Diretrizes Curriculares Nacionais para a Educação das Relações Étnico-Raciais e para o Ensino de História e Cultura Afro-Brasileira e Africana (2013); Matriz Curricular para a Educação das Relações Étnico-Raciais na Educação Básica (2016); . Diante da constância com que o tema se faz presente em leis, diretrizes curriculares, planos nacionais, estaduais e municipais e diversos documentos oficiais, pode-se dizer que há certo consenso da importância de trabalhar a diversidade em todos os âmbitos educacionais. Por outro lado, apesar dos avanços e do amparo legal nos documentos normativos, parece-me importante discutir os modos práticos para implementar a diversidade étnico-racial nas vivências escolares.

Quero problematizar a diversidade étnico-racial não apenas enquanto "conteúdo" dos componentes curriculares, como sugerem as Leis $10.639 / 03,11.645 / 08^{1}$ e a maior parte dos documentos oficiais, mas principalmente como uma abertura para diferentes epistemologias, cosmologias, para diferentes possiblidades de transmissão e produção do conhecimento. Isto implica revisão de valores e conceitos, reposicionamento de hierarquias, modificações das estruturas espaciais, entre outros aspectos. Desta perspectiva que apresento a seguir algumas reflexões a partir de minha atuação enquanto professor da disciplina artes-música.

Há cerca de seis anos sou professor de uma escola pública municipal onde leciono a disciplina curricular artes-música para crianças de seis a dez anos de idade. Desde que comecei a atuar na escola desenvolvo atividades com o tema da diversidade étnico-racial. Trabalhar com este tema me despertou dúvidas, impasses, alegrias e frustrações, em especial, no tocante aos modos como operar com este conhecimento na escola. Neste texto vou refletir sobre a diversidade étnico-racial a partir de minha 
própria experiência enquanto professor e em diálogo com as teorias etnomusicológicas e antropológicas, áreas que cursei no mestrado e no doutorado enquanto trabaIhava na escola. Neste texto dialogo pouco a produção recente da área da Educação Musical, uma vez que não houve fôlego suficiente para este aprofundamento no momento. Entretanto, alerto que os problemas aqui levantados são objetos de reflexão sistemática na literatura produzida pela Educação Musical, inclusive de forma dialógica com a Etnomusicologia e a Antropologia. Os avanços teóricos destas três áreas vem contribuindo significativamente para questionar hábitos, costumes e valores enraizados nas práticas escolares, como: a excessiva abstração promovida pela escola em detrimento dos contextos de prática; a ideia evolucionista de progresso na aquisição de conhecimentos; a noção de aprendizagem por passos sucessivos e previsíveis; a ênfase absoluta na escrita e na linguagem em detrimento de outras formas de saber, como o conhecimento oral, imagético, artístico, mitológico, ritualístico, xamânico; a centralidade da escola como o lugar mais legítimo de ensino e aprendizagem; a escolarização da criança, tornando-a sinônima de aluna e aprendiz, retirando sua autonomia, e ignorando seus saberes e experiências.

A perspectiva antropológica nos mostra que olhar para os processos educativos é importante não só para compreensão do sistema escolar, mas como um elemento fundamental da dinâmica cultural. Neste caminho, quero refletir neste texto sobre a escola não só como lugar de aprendizagem, mas como um lugar de fronteira, um espaço de contato e intercâmbio entre populações e conhecimentos diversos (TASSINARI, 2012a). As antropólogas Tassinari e Cohn propõem o termo "escola como fronteira" ao tratar das escolas indígenas nas aldeias.

\begin{abstract}
A escola nas aldeias como instituição alienígena, como um espaço ocidental incrustado na aldeia, produtor de mudanças que ameaçam a própria sobrevivência indígena. A segunda abordagem reconhece as escolas como espaços apropriados pelos índios, cujos conhecimentos e práticas são ressignificados segundo uma lógica nativa, ou, ainda, com uma instituição 'domesticada' segundo costumes indígenas. Propõe-se então, alternativamente, considerar a escola como um espaço de contato no qual os próprios polos (índio/não índio) aparecem como radicalmente diferentes, embora estejam de fato imbricados. [...] Seu modelo aponta não só para a comunicação, mas também para situações de interdição, de intercâmbio, que reforçam e reproduzem a diferença entre os participantes da interação, e esses dois movimentos, ou momentos, são igualmente produtivos para compreender a situação presente nas escolas indígenas, por questionar o caráter naturalizado das 'fronteiras interétnicas' (TASSINARI; COHN, 2012, p. 266).
\end{abstract}

Quero propor aqui, em diálogo com as autoras, qualquer escola que considere a diversidade étnico-racial como fundamento de suas práticas pode ser entendida como um "espaço de fronteira", um lugar de circulação e aprendizagem de conhecimentos diversos, um espaço de contato entre populações e saberes. Para isso, a diversidade étnico-racial na escola não pode se limitar a uma discussão sobre conteúdos. Ainda que os conteúdos se proponham a trabalhar a diversidade, os modos de operação es- 
colar, seus métodos, suas rotinas, podem desfigurar os saberes tradicionais e étnicos, constituindo-se mais em uma antropofagia cultural do que uma abertura efetiva para a diversidade de conhecimentos humanos.

\section{Apreciação musical: por um ouvido dançante}

Um dos eixos que norteiam o ensino da música é a apreciação, em conjunto com a criação, execução, a compreensão dos elementos históricos e estruturais da música, entre outros. Diversos documentos, matrizes e diretrizes curriculares apontam para a necessidade de conhecer repertórios das mais diversas manifestações culturais, em especial aquelas formadoras da cultura brasileira, como africanas, indígenas, portuguesa, assim como da cultura erudita, popular, folclórica, do Brasil e do estrangeiro. Nos últimos anos, vem-se questionando a apreciação desenvolvida a partir dos pressupostos racionalistas e intelectualistas, na qual o silêncio faz-se fundamental, assim como os domínio dos corpos. Um teórico bastante conhecido no campo da música tem como título de sua obra a expressão "O Ouvido Pensante" (SCHAFER, 1991). O título do livro simboliza a conexão entre mente e audição como caminho ideal da compreensão musical. Entretanto, tal perspectiva de um ouvir racional, revestido de um ideal de seriedade, tem seu valor e faz sentido se conectada a um tipo específico de concepção musical, valorizada em uma determinada sociedade, em um momento histórico específico. Ou seja, neste caso, as práticas musicais eruditas de meados do século XX inspiradas na tradição clássica europeia. Transpor esta noção para as manifestações africanas, afro-brasileiras, indígenas e demais povos tradicionais pode ocasionar distorções sobre o entendimento daquela cultura e consequentemente para o entendimento da sua música.

Em contraposição a Schafer, o antropólogo Allan P. Oliveira (2015) sugere o termo "O ouvido dançante" para tratar de algumas formas escuta, em especial no campo da música popular. Ele argumenta que muitos gêneros englobados sob o termo "música popular" surgiram e se popularizaram profundamente relacionados à dança. Para o autor, uma escuta aberta ao corpo e à dança será capaz de compreender de forma mais ampla os diferentes os significados atribuídos à música. Certos tipos de músicas, não foram feitas para serem apenas ouvidas, mas dançadas, coreografadas, expressadas com o corpo em movimento. Podemos ouvir uma música e "falar de motivos, tópicas, ritmos; podemos analisar letras e objetos físicos: tudo isto, em alguns contextos, é secundário para aquilo que a música serve, a dança" (OLIVEIRA, 2015, p. 10). Apesar da discussão do autor ter como foco as análises históricas e etnográficas, creio que pode contribuir significativamente para pensar sobre o ensino de música.

Nesta mesma direção, o etnomusicólogo John Blacking (1974), em seu estudo sobre a etnia Venda da África do Sul, aponta que, a eficácia funcional da música é mais importante para os ouvintes daquele lugar do que sua complexidade ou simplicidade sonora. Ou seja, para compreender o papel da música dos povos tradicionais, importa muito mais estudar o efeito da música, o valor, a função, os atos humanos de produzir sentido, do que seus elementos estruturais, sonoros, como harmonia, escalas, melodia. Para ele, a função principal da música é cooptar as pessoas para experiências em 
comum dentro do âmbito de sua experiência cultural, e este aspecto antecede sua tradução em signos e símbolos. Apesar de Blacking dirigir seus argumentos para o estudo etnográfico da música de outros povos, penso que é válido também para refletir sobre a educação da diversidade étnico-racial na escola, em outras palavras, uma educação que promova uma abertura para o outro, que aproxime concepções musicais, que estabeleça relações e contatos.

Jonathan Hill (2014) utiliza o conceito "musicalização do outro" para mostrar que os povos indígenas utilizam a música como forma de criar espaços de transformação que permitem o reconhecimento da alteridade do outro. Trata-se de um espaço social para o diálogo, criação ou celebração de alianças, troca de trabalho, comida, bebida e outros bens materiais, não só entre aldeias indígenas, mas entre índios e não-índios, seres não humanos, animais e espíritos. A música opera, portanto, como uma forma de reconhecimento, de trazer pra si, de incorporação, de "domesticação da alteridade - não para eliminá-la ou consumi-la, mas para criar um espaço social no qual comunidades de pessoas podem interagir com a alteridade em meios que promovam o convívio harmonioso, a intensidade emocional em proporção, e um fazer colaborativo da história por meio do engajamento de outrem" (op. cit., p. 36). É este potencial da música como forma efetiva de comunicação entre povos que precisa ser desenvolvida na educação das relações étnico-raciais.

Os problemas de uma "audição racional" nas práticas de apreciação musical encontra paralelo com a ênfase na escrita para o estudo de outros povos e etnias cuja base de conhecimento reside na oralidade e na experiência cotidiana. A antropóloga Clarissa Melo (2014) em seu estudo com os povos Guarani descreve os impasses entre conhecimento científico e conhecimentos indígenas, em especial no tocante aos processos de produção, aquisição e transmissão de conhecimento para esses grupos. A autora argumenta que os conhecimentos indígenas possuem mecanismos próprios para sua aquisição e transmissão que estão ligados a um contexto de prática. Melo (2014) recorre à noção de "disposições adequadas" de Tim Ingold, argumentando que o mecanismo da escrita transmite dados e conteúdos sem as disposições adequadas em relação ao modo como tais conhecimentos são produzidos e transmitidos.

Assim, pensar em "disposições adequadas" é valorizar "a forma de aprender e não apenas o conteúdo - o que se aprende" (MELO, 2014, p. 314), é propiciar "um preparo do corpo para aquisição de certos conhecimentos" (op. cit., p. 298). Neste sentido, ela argumenta que para entender o pensamento indígena é preciso fazer, vivenciar, conviver, sentir, ou seja, a aprendizagem precisa buscar conexão com o contexto e a experiência. Trata-se de um aprender que se efetua "como/na prática" - para usar termo de Jean Lave (2015) - , ou seja, aprende-se fazendo e, ao fazer, o conhecimento não é apenas transmitido, mas atualizado, resignificado, novos sentidos são produzidos. A autora recorre a Lévi-Strauss para argumentar que na "ciência moderna hegemônica" imperam conceitos, abstrações, enquanto que os conhecimentos tradicionais trabalham com percepções, cheiros, sabores, cores, sons, movimentos, relações, daí a "importância da materialidade como matriz do raciocínio" para o entendimento dos conhecimentos tradicionais (MELO, 2014, p. 312). 
Portanto, não basta ler sobre os povos indígenas para compreendê-los, "pois muito se perde quando se traduz para o papel" (op. cit., p. 313). Do mesmo modo, a apreciação das músicas indígenas, quando limitada a um ouvir pensante, será insuficiente para o entendimento abrangente daquela manifestação musical. A percepção musical precisa expandir-se para outros sentidos além da escuta, outros órgãos do corpo além do ouvido, assim como uma abertura para relações com os outros para além de uma conexão introspectiva com a própria mente.

Ainda em relação às "disposições adequadas", no Congresso Nacional da ABET que aconteceu na UFSC em 2015, participaram das mesas redondas representantes das sociedades indígenas para falar sobre sua cultura. O jovem Vherá Poty Benites da Silva, convidado para uma mesa sobre Etnomusicologia e Educação Musical, bastante desconfortável com o ambiente, disse algo assim: "me pediram para explicar sobre minha música, a música que fazemos na nossa aldeia, mas vai ser muito difícil fazer isso aqui neste auditório, com esse monte de cadeiras e com todo mundo sentado, me olhando com cara séria, seus notebooks no colo". Então, ele convidou todos para se levantarem e virem até a frente. Muito não aceitaram o convite. Formou uma roda, cantou e dançou por uns quinze minutos com aqueles que se dispuseram a participar. Depois disso, fez um breve comentário de cerca de dez minutos, a título de complementação (talvez para satisfazer a outra parte da plateia que não interagiu). E assim usou seu tempo disponível para sua exposição. Outros representantes de povos tradicionais que estavam nas demais mesas redondas deste evento não usaram a mesma estratégia e ficou evidente a frustração de alguns deles em não conseguir estabelecer a comunicação desejada, em alguns casos, notadamente em seus discursos, quando, por exemplo, durante sua exposição um senhor disse algo como: "Parece que não estou falando com ninguém. Vocês não estão reagindo. Tem alguém aí?".

Melo (2015) descreve situação semelhante ocorrida em um Seminário intitulado "Sábias Indígenas", direcionado aos estudantes do curso de Licenciatura Intercultural Indígena da UFSC, no qual algumas mulheres Guarani foram convidadas para falar sobre os cuidados relativos ao parto, gestação e espiritualidade. Neste caso, elas não conseguiram contornar a situação para falar sobre o assunto e recusaram-se a seguir daquela maneira. Apesar do público ser constituído em sua maior parte por indígenas - diferentemente do caso anterior -, ainda assim elas argumentaram que era necessário um local adequado que não fosse um auditório de um hotel, pois ali não poderia constituir-se um ambiente de troca de saberes.

Nota-se, com isso, que questões sobre diversidade étnico-racial não estão limitadas à conteúdos, mas diretamente implicada com a representatividade, ou seja, a diversidade étnico-racial dos professores, dos estudantes e demais agentes educativos. O desconforto das populações tradicionais diante das formas escolarizadas pode constituir-se um caminho para promover novas estruturas escolares, outras formas de produção e transmissão de conhecimento.

Retomando o caso da apreciação musical, por vezes, uma alteração na forma de organizar o espaço pode fazer diferença significativa na aprendizagem e compreensão de uma determinada expressão cultural. Um ambiente excessivamente formal, com uma 
sala cheia de mesas e cadeiras pode descaracterizar as diversidade de produção e transmissão de saberes tradicionais e étnicos. Uma apreciação musical diversificada pode ser feita em roda, sentados ao chão, usando outros ambientes da escola e da comunidade, movendo-se pela sala, dançando, por meio de alguma brincadeira, enquanto se faz outra atividade, em interação com os colegas. A seguir, vou ilustrar brevemente com três atividades de apreciação que costumo desenvolver em sala de aula com crianças de seis a dez anos, afim de sugerir possibilidades para uma escuta que envolva o outro, interações, corpo, movimento, pensando em "disposições adequadas".

(1) O objetivo era aprender um música nova, uma canção tradicional sul africana intitulada "Sansa Kroma e Cangoma"2. A música tem uma letra extensa e com palavras complexas para a idade das crianças com as quais trabalho. Minha intenção era fazer algumas atividades de apreciação para depois passar para atividades de execução, como tocar, cantar, improvisar. Para poder ouvi-la inúmeras vezes, fiz uma brincadeira com as crianças dispostas em círculo, usando uma bola. A brincadeira foi estruturada da seguinte maneira: uma criança circulava por detrás da roda com uma bola em mãos. Todas tinham que estar atentas à gravação. Ao ouvir uma palavra específica da letra, previamente determinada, a criança que estava circulando colocava a bola atrás de um colega que estava sentando. Este último pegava a bola, se levantava e corria atrás do colega que circulava detrás da roda antes que este tomasse o seu lugar. Como variações, em vez de ouvir uma palavra, a bola foi colocada atrás do colega ao ouvir uma determinada seção da música (A B C), ao ouvir o refrão, um instrumento musical, um acorde específico, uma fermata, um ralentando. Inúmeras variações são possíveis a depender do conteúdo musical que está sendo abordado. Com essa brincadeira, foi possível brincar com a mesma música uma aula inteira. A apreciação musical tornou-se um momento descontraído, utilizando diversas partes e sentidos do corpo, com interações entre os amigos de sala, muitas risadas, mas ao mesmo tempo, atentos à música e a seus elementos.

(2) Em outra aula, o tema foi direcionado às músicas brasileiras de carnaval. Selecionei algumas gravações referenciais, com atenção especial, aos sambas e marchinhas. Enquanto ouviam a música, podiam dançar e caminhar pela sala, livremente, sozinhos ou em pequenos grupos, ao estilo de desfile de rua. Subitamente a canção era interrompida e todos tinham que sentar imediatamente em seus lugares. Ao sentar, comentávamos brevemente sobre alguns elementos musicais (como estilo, gênero, forma), suas sensações, algo a respeito da letra da música. Algumas letras de carnaval são ótimas para discutir temas como racismo, xenofobia, homofobia, e diversos tipos de preconceitos. Após uma breve reflexão de no máximo três minutos, passávamos para outra música e assim sucessivamente até o fim da aula. Com isso, a apreciação envolveu, além de debates, dança, corpo, movimento, interações e sensações diversas.

(3) Em outra ocasião, o objetivo da aula era conhecer um instrumento musical africano, a mbira. Para isso, levei dois exemplares do instrumento que eu tinha à dis- 


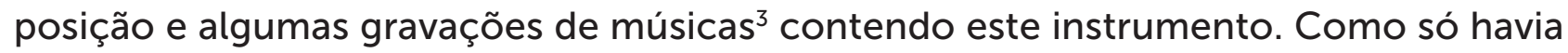
dois exemplares do instrumento, primeiro mostrei as possibilidade de manuseio e falei sobre sua origem. Em seguida, as crianças formaram pequenos grupos. Cada uma recebeu uma folha com desenhos de mbiras para colorir. Na mesma folha, algumas atividades textuais sobre o instrumento. Enquanto pintavam, liam e escreviam, também ouviam as gravações com a mbira. Simultaneamente, os dois exemplares que havia do instrumento foram passando de grupo em grupo para experimentarem-nos. Assim, a apreciação consistiu em ouvir, experimentar, ler, pintar, conversar e trocar experiência com os colegas do grupo, tudo ao mesmo tempo, sem necessidade de fracionar o aprendizado em etapas.

Não apenas as disposições adequadas são importantes para tratar de determinados conhecimentos, mas também considerar que as próprias noções de aprendizagem, as concepções de infância/criança, adquirem diferentes significados e valores em cada contexto étnico-racial.

Tassinari alerta que no contexto indígena, as crianças "são elemento-chave na socialização e na integração de grupos sociais e os adultos reconhecem nelas potencialidades que as permitem ocupar espaços de sujeitos plenos e produtores de sociabilidade" (TASSINARI, 2012b, p. 18). Ao contrário da nossa sociedade que segrega as crianças em tempos e espaços distintos dos adultos, assim como as exclui das esferas decisórias, nestes grupos étnicos, "as crianças não são segregadas em 'espaços educativos', mas bem ao contrário, ocupam posições centrais e mediadoras da vida social" (TASSINARI, 2012a, p. 281).

A perspectiva diacrônica e evolucionista de criança como um ser em desenvolvimento que um dia se tornará um indivíduo pleno (fase que só se concretiza plenamente na fase adulta); a ideia de infância como um universo caracterizado pela fantasia e diversão, cujas atitudes não têm implicações sérias e importantes na vida social; a noção de criança como um ser ainda não preparado para a vida social; a ideia de criança como ser aprendiz por excelência, limitada à condição de aluno, cujos saberes, experiências e visão de mundo não têm valor significativo; tais noções não encontram correspondência nas sociedades indígenas, revela Tassinari. Ao refletir sobre a educação indígena, a autora propõe "incluir as crianças na categoria das pessoas que 'ensinam', especialmente das que 'ensinam coisas relevantes'" (TASSINARI, 2012a, p. 285) reconhecendo-as como elos importantes da corrente do ensino e da aprendizagem. "As crianças devem ser vistas como ativas na construção e determinação de sua própria vida social e não somente como receptores passivos de estruturas e processos sociais" (TASSINARI, 2014, p. 100). Portanto, uma educação escolar comprometida com diversidade étnico-racial precisa desnaturalizar a posição da criança como aprendiz e do adulto como aquele que sabe e ensina.

Clarice Cohn (2005), a partir de seu um estudo com os povos indígena Kayapó Xikrin, ressalta que o entendimento de infância, criança e aprendizado varia de acordo 
com o contexto sociocultural e histórico de onde provêm. Ela propõe pensar a criança não como aquela que não sabe ou sabe menos, mas que sabe outra coisa. A autora constata que a criança indígena atua na criação de relações sociais e nos processos de aprendizagem e produção de conhecimento. Disso decorre que tomar o ponto de vista das crianças é importante não apenas para saber como elas pensam, mas trata-se de considerar uma forma particular de conceber o mundo que tem sérias implicações na dinâmica social. Em diálogo com Cohn, Tassinari revela que na concepção indígena de infância o mundo das crianças e o mundo dos adultos não estão separados, mas profundamente interligados. Os indígenas reconhecem a capacidade de decisão e agência das crianças, as reconhecem como mediadoras das várias esferas cosmológicas, como mediadoras de diversos grupos sociais e como sujeitos que desempenham um papel importante na produção e transmissão de conhecimento.

Charlote Hardman (2001), em seu estudo de Antropologia da Criança, sugere que o pensamento da criança tem uma estrutura diferente do pensamento do adulto. Trata-se de um segmento social marcado por suas próprias crenças, valores e interações que são exclusivos delas. Assim, as crianças e seus saberes devem ser considerados a partir de seu próprio pensamento, sua própria lógica, e não apenas como recebedores de ensinamentos dos adultos. Ou seja, como elas pensam, como elas classificam ou entendem o mundo ao seu redor, como elas entendem o mundo das crianças e o mundo dos adultos. Nese sentido, a autora critica as noções teóricas que colocam a criança em um estágio primário do desenvolvimento humano, visando unicamente formá-la para a vida adulta, sem considerar a criança em si com um ser humano integral e pleno.

\section{Prática musical: fazer música é como falar}

$\mathrm{Na}$ etnomusicologia, um pesquisador que trouxe importantes reflexões para a Educação Musical foi John Blacking (1967). Na década de 1960 ele foi estudar um povo da África, conhecido como Venda. Em seu estudo, encontrou uma sociedade em que todas as pessoas eram musicais. Isto não quer dizer que não havia diferenciação, ou seja, não quer dizer que todas as pessoas eram musicalmente iguais, mas sim que todas as pessoas se sentiam em alguma medida confortáveis para tocar, cantar e falar sobre música. Desde muito pequenas, as crianças Venda eram envolvidas em diferentes tipos de performances musicais. Blacking verificou que fazer música entre os Vendas é algo tão natural como falar. Assim como todo ser humano tem capacidade e potencial para linguagem, entre os Vendas todos têm capacidade e potencial para a música, isso faz parte da normalidade. Ou seja, a habilidade para música não é algo excepcional e reservada a poucos.

Diante disso, Blacking passou a questionar porque em sua própria sociedade (moderno-ocidental) há pessoas anti-musicais, ou não-musicais, para usar seus próprios termos. Por que em sua sociedade fazer música é um atividade reservada a poucos escolhidos? Por que muitas pessoas se sentem incapazes até mesmo de falar sobre música? Ao comparar diversos contextos socioculturais, Blacking constata que fazer música é uma capacidade inata de todo ser humano e que as condições culturais e sociais é que esti- 
mulam ou anestesiam a habilidade musical. No caso da sociedade moderna ocidental, o autor aponta a divisão social do trabalho, a fragmentação do conhecimento, a exclusão social, o tecnicismo, como fatores que conduziram para desmusicalizar alguns e a hipermusicalizar outros. Apesar do dom e do inatismo ser uma questão bastante discutida na Educação - há uma vasta literatura apontando que o contexto e as condições sociais são mais decisivas do que uma suposta pré-disposição -, nem sempre na prática em sala de aula conseguimos aplicar as reflexões teóricas e acabamos por investir mais em alguns alunos a partir de em uma suposta musicalidade manifesta. Em muitos casos, não por falta de conhecimento, mas devido as condições materiais, as rotinas escolares, a fragmentação do tempo e das disciplinas, as demandas burocráticas da atividade docente, entre outros fatores que envolvem a complexidade do ensino curricular.

Quando ingressei na escola como professor de música do Ensino Fundamental, tive sérios dilemas ao lidar, por exemplo, com a distribuição dos instrumentos musicais: quem toca, quem canta, quem fica com os instrumentos mais graves ou mais agudos, quem fica na percussão, quem toca a melodia na flauta. Em geral, entre as crianças havia um fascínio pelos tambores, quase todas queriam tocar este instrumento. Também havia uma preferência pelos os instrumentos mais sonoros, como agogô, tamborim, os quais se destacavam entre os demais. Nas primeiras aulas, nas atividades mais experimentais, o critério que eu costumava usar era o interesse manifesto de cada uma. Em uma sala com 30 a 40 crianças, aquela que falava "eu!!!" mais alto, ou se atirava rapidamente para tomar o instrumento, acabava por experimentar mais instrumentos e a utilizá-los por mais tempo. Aquelas crianças mais tímidas, ficavam às vezes sem tocar, ou tocavam menos. Com o passar das aulas, na medida em que o instrumento precisava ser inserido em um arranjo musical, até mesmo para uma futura apresentação, passei a usar outro critério de seletividade: aquelas crianças que conseguiam manter um ritmo mais regular, as aparentemente mais habilidosas, com maior facilidade na execução, acabavam por serem escolhidas.

Ao final, acabava por constatar que poucas crianças conseguiam segurar o ritmo com precisão ao longo de toda música, de modo que, os instrumentos prediletos da turma, ficaram por um longo tempo, ao menos durante os ensaios para as apresentações, em posse de um número reduzido de alunos. Aquelas crianças que identifiquei como "menos ritmadas", cantaram ou ficaram com os chocalhos e outros instrumentos mais leves. Em algumas situações, foi possível atender o desejo das crianças, mas em outras não. Isto gerou inúmeros descontentamentos. Observando as apresentações de alunos de meus colegas professores música, percebo que os instrumentos musicais, na maior parte das vezes, também ficam nas mãos de um pequeno grupo. Ainda que as escolas do município disponham de inúmeros instrumentos musicais, a maior parte dos alunos se limita a cantar nos arranjos. Noto na prática de meus colegas um receio e uma dificuldade em trabalhar com instrumentos musicais, talvez, devido a se depararem com os mesmos dilemas que eu enfrentei.

No meu caso, percebi que essa seletividade gerou descontentamentos na turma ao ponto do pai de um aluno vir me questionar sobre eu não deixar seu filho tocar tambor. Não disse ao pai que o filho era desritimado - ou anti-musical, para usar o termo 
de Blacking -, embora, na minha atuação enquanto professor, eu estava colocando seu filho e muitos outros da turma exatamente nesta posição. A inquietação do pai ecoava também no protesto de outra criança que ficou indignada por não tocar o agogô e recusava-se participar dos ensaios se não tivesse seu desejo atendido. Ecoava também na insatisfação de algumas crianças que queriam fazer o solo e outras tantas que não tiveram suas preferências atendidas.

Naquela primeira experiência letiva não encontrei solução imediata para o dilema. A apresentação de final de ano foi muito aplaudida pelos familiares, alunos e funcionários da escola, mas a situação pelo qual as crianças e eu passamos durante os muitos ensaios me fez refletir sobre minhas ações pedagógicas. Hoje compreendo que o problema não eram as crianças nem o repertório musical escolhido, mas a concepção de arte eu estava produzindo em sala com as crianças e os processos educacionais que eu utilizava para atingir os resultados almejados. Tratava-se de uma noção de arte que valorizava mais o produto final do que as relações e saberes que se constituem durante o processo; que distancia e separa o público do artista; que enrijece as obras musicais ao buscar interpretações fieis ao que está registrado na partitura; que exige máxima concentração e silêncio tanto do público quanto dos músicos; entre outros aspectos.

Nas experiências seguintes, procurei soluções para evitar a categorização de sujeitos antimusicais visando, ao contrário disso, que todos pudessem se sentir igualmente capazes de realizar qualquer função na prática música feita em sala de aula. Passei a concentrar-me não tanto na música, no repertório em si, mas, para retomar o caso da sociedade Venda, nos princípios e práticas epistemológicas faz com que todas as pessoas (no caso, todas as crianças da turma) possam se sentir musicais. Ou seja, os princípios que possibilitam sentir a música enquanto parte de si, parte de sua constituição humana; e não algo reservado a poucos. Neste sentido, a seguir, compartilho algumas experiências de atividades desenvolvidas em sala de aula.

O objetivo da atividade era distribuir os diversos instrumentos musicais de percussão entre as crianças da turma para em seguida realizar algumas experiências sonoras com os mesmos. A organização da atividade se deu da seguinte maneira: as crianças se organizaram em roda. No centro foram colocados todos os instrumentos de percussão já conhecidos e experimentados pela turma em atividades anteriores. Uma criança de cada vez foi até o centro e escolheu um instrumento para um colega, entregando-o nas mãos dele. Aquele que recebia o instrumento escolhia um instrumento para um outro colega e, assim, sucessivamente até todos terem seu instrumento em mãos. Enquanto a atividade de escolha ocorria, o professor executava um ritmo simples ao pandeiro. Aqueles que recebiam seu instrumento passava imediatamente a tocar o ritmo junto com o professor, cada um ao seu modo. Quando todos estavam com seus instrumentos em mãos, passamos para atividades de percepção, imitação rítmica e improviso. De tempos em tempos, havia troca de instrumentos, fazendo-os circular pela roda, para que as crianças pudessem experimentar a maior quantidade de instrumentos possíveis.

Os improvisos e imitações foram realizados da seguinte maneira: todos estavam sentados em círculo, cada criança já com seu instrumento de percussão em mãos. No centro, uma caixa-de-guerra para fazer os solos. Com um pandeiro, o professor execu- 
tava um ritmo de capoeira e as crianças o acompanharam a seu modo, com seus instrumentos. Em certos momentos, se fazia um breque, ou seja, uma parada rítmica onde todos deveriam estar atentos para instantaneamente pararem de tocar. Neste momento, uma criança ia ao centro e elaborava algumas células rítmicas com a caixa-de-guerra. A turma imitava/repetia as sequências criadas pelo solista logo em seguida, sem perder a fluência musical. Ao finalizar a seção de improviso, o ritmo de capoeira era retomado pelo professor e pela turma, enquanto isso, a criança que tinha realizado a improvisação escolhia outro colega para seguir o jogo. Assim seguiu-se até boa parte da turma improvisar com a caixa-de-guerra.

Com esta abordagem, houve uma descentralização do professor e consequente abertura para tomada de decisões por parte das crianças. Elas escolhiam os instrumentos e os colegas que iam improvisar. Com isso, as relações e interações se potencializaram durante a performance musical. Ao promover a frequente a circulação dos instrumentos musicais, eliminou-se o monopólio e privilégio de alguns em relação ao uso dos instrumentos antes mais desejados pela turma. Ninguém ficava com o mesmo instrumento por muito tempo. Não havia especialização, todos podiam fazer de tudo na aula: cantar, tocar, improvisar. Os instrumentos poderiam estar na mão de qualquer criança para a música acontecer, a eficácia da performance não dependia de ninguém em especial, de algum solista ou algum aluno mais experiente, todas se sentiam musicalmente aptas a realizar qualquer função na performance musical.

\section{Considerações Finais}

A educação das relações étnico-raciais nos convida a pensar formas diferenciadas de conceber a escola, o conhecimento, os processos de transmissão, ensino e aprendizagem. Não se trata de inserir todos os conhecimentos e modos de aprender étnicos dentro da sala de aula, tampouco reproduzir exatamente como eles acontecem no seu contexto de origem, mais sim refletir criticamente sobre a escolarização dos conhecimentos, desnaturalizar as rotinas escolares que impedem o reconhecimento de outras formas de aprendizagem, outras formas de se relacionar com os saberes e de produzi-los. Também não se trata de condenar o conhecimento científico tradicional, as rotinas e formas escolares instituídas e elaboradas ao longo de décadas, mas sim de possibilitar dentro da escola uma abertura para outros conhecimentos e formas de lidar com eles, colocando-os em situação de igualdade com os saberes já instituídos pela tradição escolar. Em um país diversos como o Brasil, a escola não pode promover apenas uma forma de compreender do mundo, uma única forma de pensar, raciocinar, agir, conhecer, produzir e de se relacionar com o outro e com o conhecimento.

\section{Referências}

ALMEIDA, M. Berenice; PUCCl, Magda D. Outras terras, outros sons. São Paulo: Callis, 2002. (Acompanha CD). 
BEAUCHAMP, Jeanete; PAGEL, Sandra Denise; NASCIMENTO, Aricélia Ribeiro do. (Orgs). Ensino fundamental de nove anos: orientações para a inclusão da criança de seis anos de idade. Brasília: Ministério da Educação. Secretaria de Educação Básica, 2007.

BLACKING, John. How Musical is Man?. Seattle and London: University of Washington Press, 1974.

BLACKING, John. Venda Children's Songs: a study in ethnomusicological analysis. Witwatersrand University Press, 1967.

BRASIL. Parâmetros Curriculares Nacionais: arte. Secretaria de Educação Fundamental. Brasília: MEC/SEF, 1997.

BRASIL. Lei 10.639/2003, de 9 de janeiro de 2003. Altera a Lei no 9. 394, de 20 de dezembro de 1996. Diário Oficial da União, Poder Executivo, Brasília.

BRASIL. Lei 11.645/08 de 10 de Março de 2008. Diário Oficial da União, Poder Executivo, Brasília.

COHN, Clarice. Antropologia da Criança. Rio de Janeiro: Jorge Zahar, 2005.

DIRETRIZES CURRICULARES NACIONAIS PARA A EDUCAÇÃO DAS RELAÇÕES ÉTNICO-RACIAIS E PARA O ENSINO DE HISTÓRIA E CULTURA AFRO-BRASILEIRA E AFRICANA. Brasília-DF. 2004.

GIOIELLI, Décio. A Mbira da beira do rio Zambeze. São Paulo: Moderna, 2007 (acompanha CD).

HARDMAN, Charlote. Can there be na anthropology of children? Childhood, v.8, n. 4, p.501-517, 2001.

HILL, Jonathan. Musicalizando o outro: Etnomusicologia na era da Globalização. In: MONTARDO, Deise L; DOMÍNGUEZ, Maria Eugênia. Arte e Sociabilidade em Perspectiva Antropológica. Florianópolis: Ed. da UFSC, 2014, p. 13-46.

LAVE, Jean. Aprendizagem como/na prática. Horizontes Antropológicos, Porto Alegre, ano 21, n. 44, p. 37-47, jul./dez. 2015.

MATRIZ CURRICULAR PARA EDUCAÇÃO DAS RELAÇÕES ÉTNICO-RACIAIS NA EDUCAÇÃO BÁSICA. Prefeitura Municipal de Florianópolis. Secretaria Municipal de Educação. Florianópolis, 2016. 
MELO, Clarissa Rocha de. Aprendizado, percepção e conhecimento Guarani: possibilidades de diálogo entre saberes distintos. In: TASSINARI, A.; ALMEIDA, J.; RESENDÍZ, N. Diversidade, Educação e Infância: reflexões antropológicas. Florianópolis: Ed. da UFSC, 2014, p. 295-329.

OLIVEIRA, Allan Paula. O ouvido dançante: música popular entre swings e cangotes. El Oído Pensante, v. 3, n. 2, p. 1-21, 2015.

ORIENTAÇÕES CURRICULARES: expectativas de aprendizagem para a educação étnico-racial na educação infantil, ensino fundamental e médio / Secretaria Municipal de Educação - São Paulo : SME / DOT, 2008.

PLANO NACIONAL DE IMPLEMENTAÇÃO DAS DIRETRIZES CURRICULARES NACIONAIS PARA A EDUCAÇÃO DAS RELAÇÕES ÉTNICO-RACIAIS E PARA O ENSINO DE HISTÓRIA E CULTURA AFRO-BRASILEIRA E AFRICANA. Ministério da Educação. Secretaria de Educação Continuada, Alfabetização, Diversidade e Inclusão. Brasília: MEC, SECADI, 2013.

SCHAFER, Murray. O ouvido pensante. São Paulo: Fundação Editora da UNESP, 1991.

TASSINARI, Antonella. e COHN, Clarice. Escolarização indígena entre os Karipuna e Mebengokré-Xikrin: uma abertura para o outro. In: TASSINARI, A; GRANDO, B; ALBUQUERQUE, M. (Orgs). Educação Indígena: reflexões sobre noções nativas de infância, aprendizagem e escolarização. Florianópolis: Ed. da UFSC, 2012, p. 247-274.

TASSINARI, Antonella. A sociedade contra a escola. In: TASSINARI, A; GRANDO, B; ALBUQUERQUE, M. (Orgs). Educação Indígena: reflexões sobre noções nativas de infância, aprendizagem e escolarização. Florianópolis: Ed. da UFSC, 2012a, p. 275-294.

TASSINARI, Antonella. Introdução: sobre noções nativas e antropológicas em educação indígena. In: TASSINARI, A; GRANDO, B; ALBUQUERQUE, M. (Orgs). Educação Indígena: reflexões sobre noções nativas de infância, aprendizagem e escolarização. Florianópolis: Ed. da UFSC, 2012b, p. 15-24.

TASSINARI, Antonella. Ajudando e aprendendo: a participação de crianças nas atividades produtivas da agricultura familiar. In: TASSINARI, A.; ALMEIDA, J.; RESENDÍZ, N. Diversidade, Educação e Infância: reflexões antropológicas. Florianópolis: Ed. da UFSC, 2014, p. 97-132. 